ДОМБРОВСКАЯ Анна Юрьевна - доктор социологических наук, профессор департамента политологии и массовых коммуникаций Финансового университета при Правительстве РФ (125993, Россия, г. Москва, ГСП-3, Ленинградский пр-кт, 49); доцент кафедры социально-политических исследований и технологий Московского педагогического государственного университета (119991, Россия, г. Москва, ул. М. Пироговская 1/1; an-doc@yandex.ru)

\title{
ГРАЖДАНСКИЙ АКТИВИЗМ МОЛОДЕЖИ В СОВРЕМЕННОЙ РОССИИ: ОСОБЕННОСТИ ПРОЯВЛЕНИЯ В ОНЛАЙН- И ОФЛАЙН-СРЕДАХ (по резУЛЬтатаМ
}

\section{эмпирического исследования)}

Аннотация. В статье раскрываются эмпирические показатели проявления российской молодежью интереса к различным формам гражданского активизма онлайн и офлайн. Основным методом сбора информации служит массовый онлайн-опрос российской молодежи. Устанавливается зависимость между принадлежностью российского молодого поколения к различным кластерам протестного потенциала («лидеры», «активисты», «вовлеченные», «зрители») и спецификой проявления интереса к различным типам гражданского активизма в цифровой и реальной средах. Автор делает вывод о высоком потенциале развития конвенциональных форм гражданской активности российской молодежи в онлайн-сетевом пространстве. Результаты исследования могут представлять интерес для профильных комитетов Государственной думы и Общественной палаты, отделов органов власти по работе с молодежью, вузов и способствовать разработке мер по преодолению деструктивных форм политической социализации молодежи, формированию установок на конвенциональный диалог молодого поколения с властью. Ключевые слова: молодежь, гражданский активизм, интернет-коммуникация, цифровое поведение, массовый онлайн-опрос

Статья подготовлена по результатам исследований, выполненных за счет бюджетныхсредств погосударственному заданию Финуниверситету.

$\mathrm{C}$ егодня наблюдается постепенное включение молодежи в политическую и гражданскую повестки, особенно заметное в онлайн-сетевом пространстве. Цифровые форматы проявления гражданской позиции довольно интенсивно осваиваются российским молодым поколением, что дает возможность говорить о планомерном развитии гражданского активизма молодежи в онлайне. Проблемное поле исследования актуализируется необходимостью ответить на вопрос, каковы наиболее востребованные российской молодежью форматы демонстрации гражданского активизма, что и служит основным исследовательским компасом эмпирического анализа. Ответ на данный вопрос позволит научно обосновать меры по развитию конвенциональной культуры гражданского активизма современной молодежи России и преодолеть риски деструктивных форм протестной активности молодого поколения в цифровой и реальной средах.

Теоретической основой исследования служат: понимание гражданского общества Дж. Локком [Локк 2014: 308], гражданской культуры в работах С. Вербы, C. Нормана и Дж. Ная [Verba et al. 1978: 46], понимание стратегии «цифровой одержимости» Г.У. Бланком [Blank, Groselj 2014]; открытие механизмов цифровой гражданской и политической активности А. Вромен [Vromen 2017]; основные положения о поколении цифрового бунта Л. Эрреры [Herrera 2012], основные результаты комплексных исследований коллектива Е.В. Бродовской 
об онлайн-сетевой гражданской активности молодого поколения России [Бродовская и др. 2019а; 2019б]. Важной для исследования также является позиция И.Н. Трофимовой относительно специфики понимания гражданского активизма, в контекст которого относятся установки на гражданский контроль органов власти для укрепления верховенства права и равенства всех перед законом [Трофимова 2016]. В этой связи в числе переменных прикладного анализа присутствуют показатели, характеризующие готовность молодежи обсуждать политические решения органов власти, социальные проблемы и стратегии их разрешения гражданским обществом.

Базовым методом сбора информации служил опрос молодежи РФ методом онлайн-анкетирования 1 , осуществленный в июле - сентябре 2019 г.

Ключевыми параметрами анкеты массового онлайн-опроса служило множество характеристик, отражающих специфику цифрового поведения российской молодежи. В данной статье сфокусируемся на модуле политических и гражданских онлайн-практик.

Обработка базы данных осуществлялась с применением осевого, кросстабуляционного, корреляционного анализа. Кластеризация базы данных онлайн-опроса российской молодежи осуществлена с применением программы SPSS Statistics 18.0.

Исследование показало, что особенности проявления гражданского активизма онлайн и офлайн в существенной степени зависят от принадлежности российской молодежи к различным кластерам, выделенным по характеру проявления протестного потенциала. Наименее представленным сегментом молодых россиян служит кластер «лидеров», их 5,1\% среди опрощенных (характеризуются готовностью осуществлять руководство и идейное сопровождение гражданских и политических протестных акций). Еще один редкий тип российской молодежи - «активисты» $(7,0 \%)$, они отличаются способностью к организационному сопровождению гражданских и политических акций; это своеобразные «правые руки» лидеров, некий «менеджмент среднего звена» данных акций. Более трети опрошенной молодежи $(37,0 \%)$ - так называемые вовлеченные со свойственной им установкой на стороннее наблюдение за политической и социальной жизнью страны; у них не наблюдаются явно выраженные установки на деятельностный компонент в реализации гражданского активизма. Наиболее распространенный кластер российской молодежи - «зрители» $(50,8 \%)$; это, по сути, абсентеисты, изредка демонстрирующие пассивный интерес к гражданской и политической повестке государства.

Проанализируем, каковы значения параметров онлайн- и офлайн- гражданской активности перечисленных сегментов российской молодежи.

Опыт подписания петиций в защиту прав людей онлайн. На рис. 1 показано, как в зависимости от типа кластера протестного потенциала опрошенные отвечают на вопрос о частоте использования ими интернет-сервисов подписания петиций. Совершенно очевидна зависимость, проявляющаяся в более частом (почти в 2 раза) многократном опыте подписания онлайн-петиций в защиту прав «лидерами», «активистами» и «вовлеченными» в сравнении со «зрителями» (см.

1 Выборочная совокупность - 1000 чел., репрезентативная по полу, возрасту, территории проживания в соответствии со статистическими данными о представленности в составе российской молодежи групп 15-19 лет, 20-24 лет и 25-29 лет и территориальной принадлежностью (в выборке воспроизведено соотношение численности молодежи во всех федеральных округах РФ). Ошибка выборки - 4,2\%. В процессе отбора респондентов и их приглашения к участию в опросе по ссылке на электронную анкету использовались социальные сети ВКонтакте, Facebook и Twitter. В ходе обработки полученных эмпирических данных выбраковке подвергались все анкеты, имеющие незаполненные ответы; по итогам проверки осуществлен ремонт выборочной совокупности. 
рис. 1). Этот параметр отражает разницу между «вовлеченными» и «зрителями», которые сходны в отсутствии большого потенциала выражения гражданского несогласия и неповиновения, однако «вовлеченные» гораздо чаще, чем «зрители», ориентированы на активность по поддержке инициатив по защите прав в формате подписания петиций с применением интернет-сервисов.

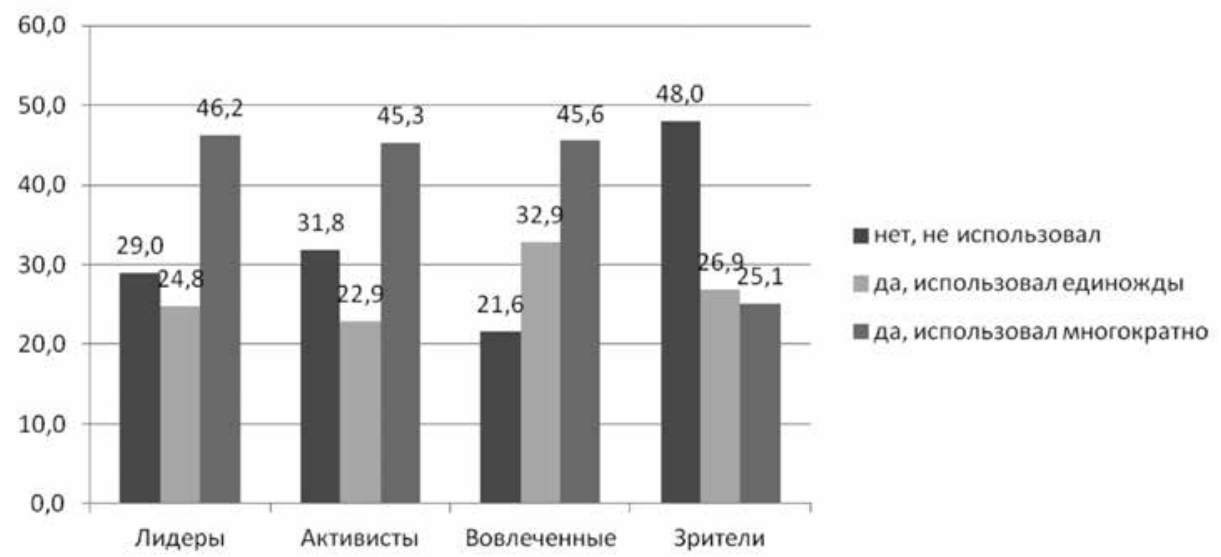

Рисунок 1. Сопряжение различных кластеров российской молодежи с частотой использования ими интернет-сервисов подписания петиций, \%

Следующий параметр устанавливает частоту прочитывания и комментирования социально-медийных сообщений о решении социальных проблем жителей города и указывает, насколько молодежь интересуется противоречиями, существующими в сфере социальной защиты и поддержки населения (см. рис. 2). Наиболее высокую степень выраженности этого показателя демонстрируют «активисты» - около трети представителей данного типа молодежи не просто читают, но и комментируют и создают авторский контент на эту тему. Модальным значением анализируемого параметра служит вариант «ино-

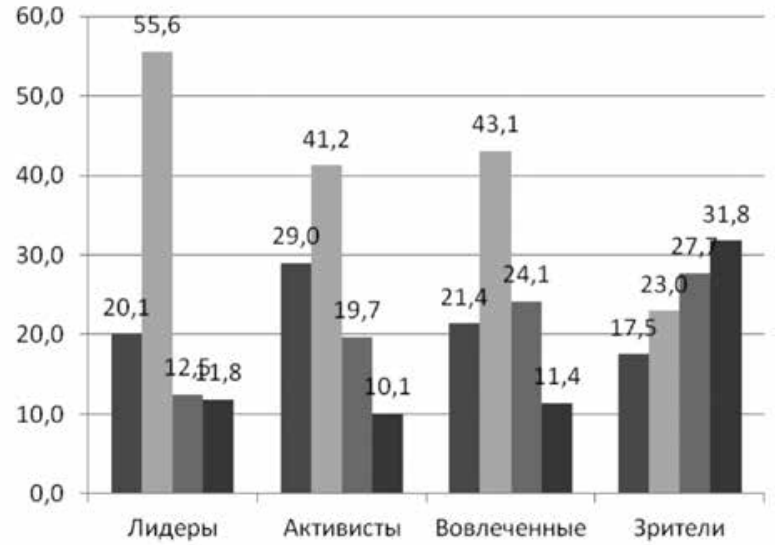

Часто читаю, комментирую, или пишу сообщения

\# Иногдачитаю, комментирую, или пишу сообщения

Очень редко читаю, комментирую, или пишу сообщения

Никогда не читаю и не пишу на эту тему

Рисунок 2. Сопряжение различных кластеров российской молодежи с частотой прочитывания и комментирования социально-медийных сообщений о решении социальных проблем жителей города, \% 
гда читаю, комментирую и пишу сообщения». Вместе с тем обращает на себя внимание фактически линейная связь, обнаруживающаяся у «зрителей»: планомерный рост доли этой части молодежи по мере роста степени пассивности в отношении социальных проблем. Таким образом, и в данном параметре «зрители» демонстрируют абсентеизм, тогда как представители остальных кластеров выражают существенную заинтересованность в обсуждении данного рода общественных противоречий.

Проявление интереса к теме защиты гражданских прав людей, меньшинств и пр. в целом представляется более значимым для российской молодежи в сопоставлении с отношением к социальным проблемам. На рис. 3 мы видим, что от четверти до трети российской молодежи в зависимости от кластера ориентированы на активное выражение своего мнения о защите человеческих прав. Обращаясь к результатам исследования, содержательно связанным с этим параметром, отметим, что призыв к защите прав личности может служить своеобразным «спусковым механизмом», триггером и наиболее эффективным средством мобилизации гражданской и политической активности российской молодежи. Вместе с тем у двух третей «зрителей» (совокупно 61,9\%) сообщения на тему защиты прав личности не вызывают существенного резонанса.

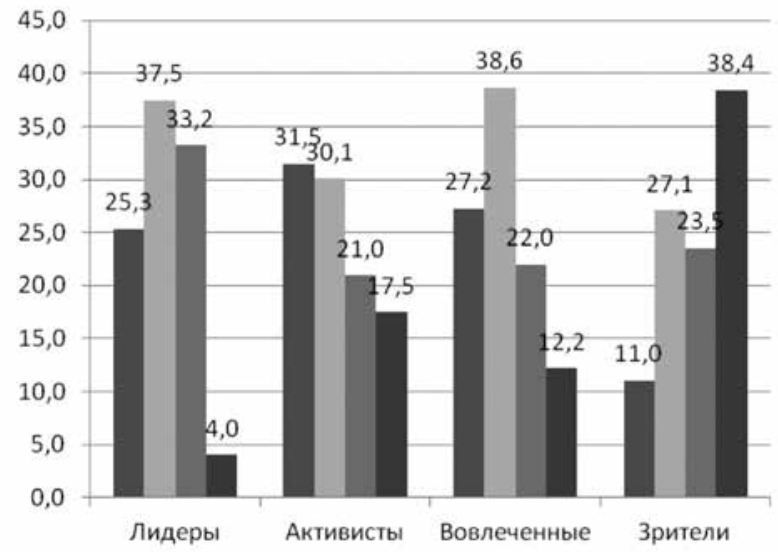

- Часто читаю, комментирую, или пишу сообщения

шногога читаю, комментирую, или пишу сообщения

- Очень редко читаю, комментирую, или пишу сообщения

- Никогдане читаю и не пишу на эту тему

Рисунок 3. Сопряжение различных кластеров российской молодежи с частотой прочитывания и комментирования социально-медийных сообщений о решении вопросов защиты прав человека, меньшинств и др., \%

Такой показатель, как частота прочитывания и комментирования социально-медийных сообщений о поддержке политических партий, кандидатов, проведении политических акций, свидетельствует о степени интереса российской молодежи к политической повестке страны. На рис. 4 показано довольно равномерное распределение долей молодежи различных кластеров по оси проявления интереса к данным темам. «Лидеры» и «активисты» сгруппировались фактически в равновесные сегменты молодежи, интересующиеся и равнодушные к политической повестке государства. «Вовлеченные» существенно реже, чем «лидеры» и «активисты», заявляют о богатом опыте комментирования и создания собственного контента на политические темы. Заметно и абсолютное преобладание отсутствия интереса «зрителей» к рассматриваемой теме. Этот параметр служит иллюстрацией зафиксированного рядом отечественных исследователей феномена так называемого неполитического гражданского 
активизма [Трофимова 2016]. Об этом свидетельствуют и результаты социальномедийного анализа, проведенного в рамках анализируемого исследования. Автоматизированное аккумулирование сообщений социальных медиа Рунета, в которых отражены маркеры политической и гражданской активности молодежи, показало, что сегмент гражданского активизма в 6 раз больше, чем сектор политического активизма (86,2\% против 13,8\% сообщений из 580000 документов, выгруженных сервисом для мониторинга социальных медиа IQBuzz за период с 01.2018 по 01.09.2019).

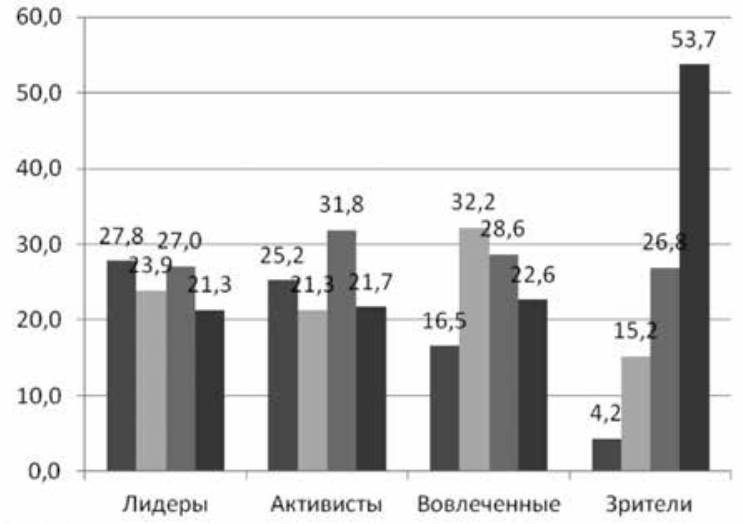

Часто читаю, комментирую, или пишу сообщения

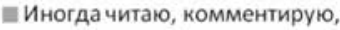
или пишу сообщения

Очень редко читаю, комментирую, или пишу сообщения

- Никогда не читаю и не пишу на эту тему

Рисунок 4. Сопряжение различных кластеров российской молодежи с частотой прочитывания и комментирования социально-медийных сообщений о поддержке политических партий, кандидатов, проведении политических акций, \%

На рис. 5 представлены эмпирические доказательства достаточно устойчивого интереса российской молодежи к волонтерской деятельности онлайн. Несмотря на то что средняя доля активно обсуждающих проблемы волонтерской активности онлайн среди «лидеров» и «активистов» почти вдвое больше, чем средний процент «вовлеченных» и «зрителей», проявляющих интерес к этой теме, следует отметить, что в сравнении с другими аналогичными параме-

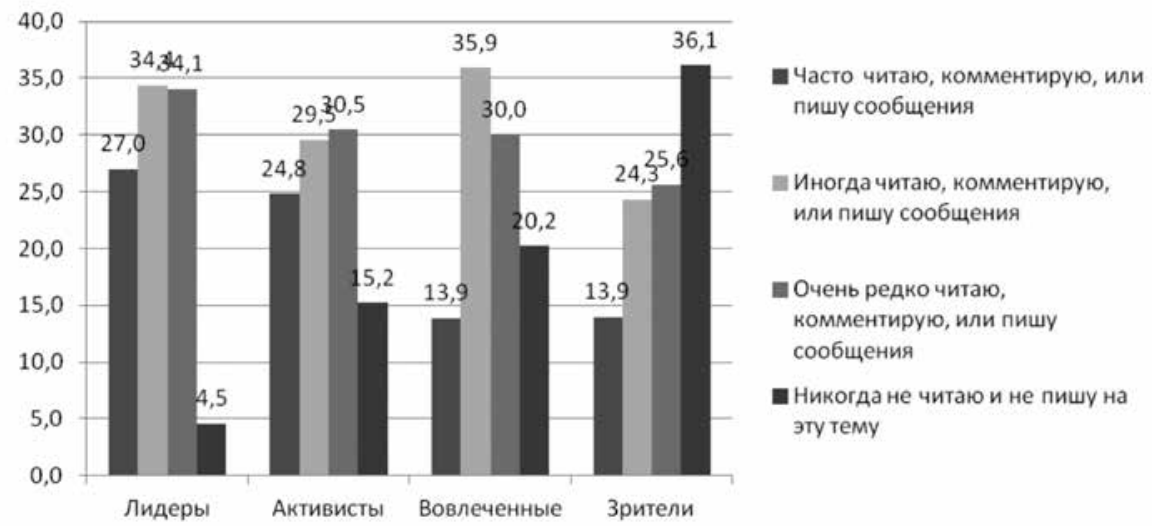

Рисунок 5. Сопряжение различных кластеров российской молодежи с частотой прочитывания и комментирования социально-медийных сообщений об участии в волонтерской деятельности онлайн, \% 
трами (обсуждение политических тем или прав личности) «зрители» проявляют в целом более уверенный интерес к волонтерству онлайн.

Заключительные два параметра демонстрируют соотношение различных типов гражданского активизма молодежи, осуществляемого онлайн и офлайн. На рис. 6 показаны преобладающие для «лидеров», «активистов» и «вовлеченных» типы гражданской активности онлайн: подписка на политические интернет-ресурсы, онлайн-ресурсы органов власти и оппозиционных сил; цифровые сообщества, обсуждающие политические темы. Вместе с тем среди «вовлеченных», и особенно среди «зрителей», обращает на себя внимание доля молодых людей, не реализующих никакие из перечисленных форматов гражданской активности. Две трети «зрителей» вовсе предпочитают никак не проявлять свою гражданскую позицию.

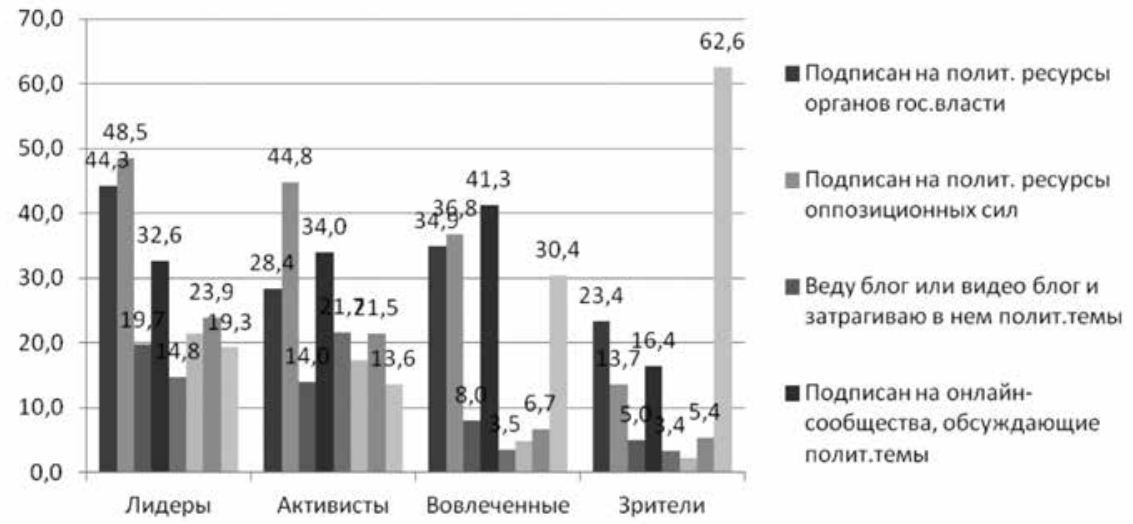

Рисунок 6. Сопряжение различных кластеров российской молодежи с частотой осуществления гражданской активности онлайн, \%

На рис. 7 показаны реализуемые молодежью разных кластеров типы гражданской активности в офлайн-среде. Среди «лидеров» доминирующими видами гражданского активизма служат статус сторонника в непарламентской поли-

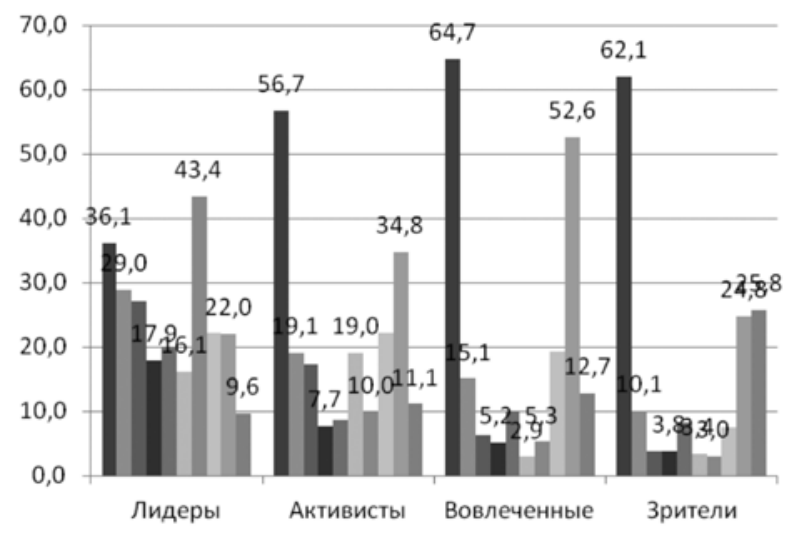
Голосование на выборах
- Участие в избирательных кампаниях в качестве агитатора
- Являюсьчленом парламентской политической партии
Являюсьчленом непарламентской политической партии
Являюсь членом общественной организации
" Имею статус сторонника парламентской полит.партии

Рисунок 7. Сопряжение различных кластеров российской молодежи с частотой осуществления гражданской активности офлайн, \% 
тической партии $(43,3 \%)$, а также голосование на выборах $(36,1 \%)$. Активисты гораздо чаще называют голосование на выборах в качестве своей основной гражданской активности офлайн $(56,7 \%)$, а также $34,8 \%$ считают подписание петиций базовым типом проявления своей гражданской позиции в реальности. Подобные доминанты отличают и «вовлеченных», а среди «зрителей», помимо голосующих на выборах, заметна группа молодежи, указывающая на то, что никакие из типов гражданского активизма для них не характерны.

Резюмируя основные результаты исследования, перечислим ключевые выводы. Молодежь, принадлежащая к разным кластерам протестного потенциала, демонстрирует различия в проявлении гражданского активизма онлайн и офлайн. Отличия в цифровом выражении гражданской позиции «лидеров» и «активистов» минимальны: оба типа относительно интенсивно создают собственный онлайн-контент по вопросам социальных проблем, защиты прав людей, развития волонтерства, однако «лидеры» несколько чаще «активистов» выражают интерес к получению информации из интернет-ресурсов политических партий, политически ориентированных сообществ и существенно реже признают участие в голосовании основной составляющей своей гражданской активности. «Вовлеченные» при довольно высоком интересе к обсуждению социальных проблем, проблем защиты гражданских прав и развития волонтерства, тем не менее, довольно часто заявляют об отсутствии интереса к реализации каких бы то ни было форм гражданского активизма как онлайн, так и офлайн. «Зрители» отличаются абсентеистским подходом фактически ко всем предложенным в опросном инструменте типам гражданской активности; это часть российской молодежи, фактически выключенная как из гражданской, так и из политической повесток. Вместе с тем сравнение онлайн- и офлайнгражданских активностей молодого поколения России позволяет говорить о довольно существенном потенциале формирования конвенциональных форм гражданского активизма в онлайн-сетевом пространстве, поскольку выявлен относительно высокий интерес значительной части молодежи к установлению широкого публичного онлайн-диалога о социальных, правовых и прочих аспектах развития российского общества.

\section{Список литературы}

Бродовская Е.В., Домбровская А.Ю., Пырма Р.В., Азаров А.А., Синяков А.В. 2019а. Влияние цифровых коммуникаций на формирование профессиональной культуры российской молодежи: результаты комплексного прикладного исследования. - Мониторинг общественного мнения: экономические и социальные перемены. № 1. С. 229-251. Доступ: https://www.monitoringjournal.ru/index.php/ monitoring/issue/view/10/6 (проверено 28.02.2020).

Бродовская Е.В., Домбровская А.Ю., Пырма Р.В., Азаров А.А. 20196. Готовность современной российской молодежи к реализации гражданской и политической активности в цифровой среде. - Власть. Т. 27. № 1. С. 91-96.

Локк Дж. 2014. Два трактата о правлении. М.: Социум. 494 с.

Трофимова И.Н. 2016. Гражданский активизм в современном российском обществе: особенности локализации. - Социс. Социологические исследования. № 4. C. 72-77.

Blank G., Groselj D. 2014. Dimensions of Internet Use: Amount, Variety, and Types. - Information, Communication \& Society. Vol. 17. No. 4. P. 417-435.

Herrera L. 2012. Youth and Citizenship in the Digital Age: a View from Egypt. Harvard Educational Review. Vol. 82. No. 3. P. 333-352.

Verba S., Norman H., Nie J., Kim J.-O. 1978. Participation and Political Equality: A Seven-Nation Comparison. N.Y.: Cambridge University Press. P. xxi + 394. 
Vromen A. 2017. Digital Citizenship and Political Engagement. London: Palgrave Macmillan UK. 278 p.

DOMBROVSKAYA Anna Yur'evna, Dr.Sci. (Soc.), Professor of the Department of Political Science and Mass Communications, Financial University under the Government of the Russian Federation (49 Leningradsky Ave, GSP-3, Moscow, Russia, 125993); Associate Professor of the Chair of Socio-Political Research and Technology, Moscow State Pedagogical University (bld. 1, 1 Malaya Pirogovskaya St, Moscow, Russia, 119991; an-doc@ yandex.ru)

\section{CIVIL ACTIVISM OF YOUTH IN MODERN RUSSIA: FEATURES OF ITS MANIFESTATION IN ONLINE AND OFFLINE ENVIRONMENTS (based on the results of an empirical study)}

Abstract. The article presents the empirical results of the study focused on the Russian youth online and offline civic activism. The main collecting data method is a mass online survey of Russian youth. Correlation between the Russian young generation belonging to various clusters of protest potential (leaders, activists, involved, spectators) and the features of its civic activism in digital and real spaces are identified. The author makes conclusion on the high potential for the development of conventional forms of online network civic activity of Russian youth. The results of the study may be of interest to the relevant committees of the Russian State Duma and the Public Chamber; departments of government departments working with youth; universities. It also may contribute to the development of measures to overcome the destructive forms of youth political socialization, the formation of the attitudes to the conventional dialogue of the young generation with the government. Keywords: youth, civic activism, Internet communication, digital behavior, mass online survey

БЕЗРУКОВА Елена Юрьевна - аспирант Института общественных наук Российской академии народного хозяйства и государственной службы при Президенте РФ (119571, Россия, г. Москва, nр-кт Вернадского, 82; vladlena2017@gmail.com)

\section{СОЦИАЛЬНО-ПОЛИТИЧЕСКИЙ ПРОТЕСТ В РОССИИ, ИЛИ «ПОЧЕМУ ЛЮДИ НЕ БУНТУЮТ?»}

Аннотация. Статья посвящена рассмотрению протестов, проходивших в российском обществе в 20182019 гг. Автор анализирует причины массового неучастия людей в публичных мероприятиях даже при наличии причин для социального недовольства. Анализ проводится на основе изучения результатов разных опросов общественного мнения о состоянии протестного потенциала в России. В статье поднимается вопрос о причинах созревания протестного потенциала в стране и проводимой в этой связи государственной политики, которая, по мнению автора, имеет тенденцию к ужесточению контроля за протестными выступлениями граждан вместо попытки выстраивания диалога. Отсюда наблюдаются две тенденции: большая часть общества начинает склоняться к политическому абсентеизму и придерживается принципа неучастия, а та меньшая часть, которая готова принимать участие в протестах, радикализируется. Ключевые слова: протест, власть, политическое участие, пенсионная реформа, диалог между властью и обществом, радикализация 